\title{
INTERFERÊNCIA DO TEOR DE ÁGUA DAS VAGENS NA COLHEITA MECANIZADA DE AMENDOIM
}

João Vitor Pires Junqueira Reis'; José Wagner ${ }^{2}$; Pedro Henrique Pain Vilares³; Adão Felipe dos Santos4; Rouverson Pereira da Silva ${ }^{5}$

'Graduando em agronomia da FCAV/UNESP, Jaboticabal, joaovitorpjunqueirareis@hotmail.com; '2Engenheiro Agronomo; ${ }^{3}$ Graduando em agronomia da FCAV/UNESP, Jaboticabal; ${ }^{4}$ Doutorando em Agronomia (Produção Vegetal), FCAV/UNESP, Jaboticabal, SP; ${ }^{5}$ Docente da FCAV/UNESP, Jaboticabal, SP.

RESUMO: A cultura do amendoim demanda duas operações para a colheita: arranquio e recolhimento, em que a segunda operação possui relação direta com o teor de água das vagens, de modo que este pode causar maiores ou menores níveis de perdas durante a colheita. Diante disso, objetivou-se avaliar as perdas no recolhimento de amendoim em dois teores de água das vagens, utilizando ferramentas do Controle Estatístico de Processo, sendo a qualidade do processo avaliada por meio das cartas de controle de média móvel exponencialmente ponderada. O experimento foi conduzido em uma área de produção de sementes de amendoim, em Luzitânia, São Paulo, Brasil, utilizando-se como tratamentos o teor médio de água das vagens de 15 e $20 \%$. Avaliou-se as perdas durante a operação (perdas da máquina, perdas da plataforma e perdas totais). Todas as variáveis analisadas encontraram-se sob controle estatístico de processo. As perdas na plataforma foram maiores do que as perdas da máquina. A correta regulagem da recolhedora deve ser realizada em função do teor de água das vagens ao longo do dia de trabalho. Existe relação das perdas na colheita com o teor de água na leira.

Palavras-chave: Perdas na colheita, umidade das vagens, controle estatístico de processo.

\section{INTRODUÇÃO}

A colheita de amendoim ocorre em duas operações, devido ao desenvolvimento fisiológico da planta. As vagens se desenvolvem abaixo do solo e são colhidas utilizando-se um arrancadorinvertedor, em seguida, as plantas são deixadas para secar parcialmente no campo antes de serem recolhidas (COLVIN et al., 2018).

Via de regra, as máquinas utilizadas na colheita do amendoim ainda carecem de tecnologia, portanto os índices de perdas nas operações podem ser elevados, contudo, sabe-se que a tecnologia não resolverá os problemas das perdas, pois essas podem acontecer por diversos fatores, incluindo o rendimento das culturas, o clima, a trilha, as configurações do sistema de limpeza das colhedoras (SAEYS et al., 2010) e a variação do teor de água existente no material colhido, o qual pode ser apontado como um dos principais fatores que ocasiona as perdas quantitativas e qualitativas, especialmente na cultura do amendoim. Esse fato faz com que seja necessário que as recolhedoras 
sejam ajustadas ao longo do dia de acordo com a quantidade do teor de água presente nas vagens, aumentando a eficiência e a qualidade no processo de colheita de amendoim, com redução de perdas e impurezas.

Para tanto, foi empregado ferramentas do controle estatístico de processo para monitorar a qualidade da operação de colheita de amendoim em dois teores de água nas vagens, com objetivo de verificar a interferência desses na ocorrência das perdas no recolhimento mecanizado de amendoim.

\section{MATERIAL E MÉTODOS}

O experimento foi conduzido em uma área de produção de sementes de amendoim, no distrito de Luzitânia-SP, Brasil, localizada próximo às coordenadas geográficas $21^{\circ} 06^{\prime} 39^{\prime \prime} \mathrm{S}$ e $48^{\circ} 14^{\prime} 09^{\prime \prime} \mathrm{W}$, com altitude e declividade de 540 metros e $2,5 \%$, respectivamente. O tipo de solo predominante é de textura franco argilosa (EMBRAPA, 2013). A variedade de amendoim utilizada foi a granoleico, semeada a $0,90 \mathrm{~m}$ entre linhas, com densidade populacional de 18 plantas $\mathrm{m}^{-1}$.

Os tratamentos utilizados foram dois teores de água das vagens (15 e $20 \%$ ), sendo coletados 16 pontos no tratamento teor de água das vagens com $20 \%$ de teor de água, e 14 pontos no tratamento teor de água das vagens 15\%, seguindo-se as premissas do Controle Estatístico de Processo, de modo que as amostras foram coletadas ao longo do tempo, de acordo com o deslocamento do conjunto mecanizado. O teor de água das vagens foi determinado de acordo com o método de BRASIL (2009).

Para proceder os cálculos de perdas e caracterizar a lavoura, estimou-se a produtividade média em uma área amostral de $2 \mathrm{~m}^{2}$, sendo $5 \mathrm{~m}$ à frente do ponto que foi avaliado as variáveis de cada tratamento. Dessa forma fez-se a média de 30 pontos, em seguida extrapolou os valores para $\mathrm{kg} \mathrm{ha}^{-1}$. Levou-se em consideração todas as vagens desenvolvidas que estavam dentro da área amostral.

Para avaliar a qualidade da operação utilizou-se os indicadores de qualidade: perdas na plataforma de recolhimento (PPR), perdas da máquina (PMR) e perdas totais na operação de recolhimento (PTR) que foram determinados com base na produtividade média de $5.500 \mathrm{~kg} \mathrm{ha}^{-1}$.

Para avaliar as perdas, quatro aros de $0,33 \mathrm{~m}^{2}$ foram lançados entre a plataforma de recolhimento e o eixo dos rodados da recolhedora trilhadora. Desta forma, todas as vagens encontradas abaixo dos aros após a passagem da recolhedora foram consideradas como perdas na plataforma de recolhimento mais as perdas visíveis da operação anterior (arranquio). As vagens acima dos aros foram consideradas como perdas da máquina, e a somatória dessas duas perdas foram consideradas como perdas totais no recolhimento.

A análise da variabilidade do processo de recolhimento mecanizado de amendoim foi realizada por meio do Controle Estatístico de Processo, com auxílio do programa Minitab ${ }^{\circledR}$, optando-se por escolher as cartas de controle de média móvel exponencialmente ponderada (MMEP), por ser mais rigorosa na análise e detectar pequenas mudanças ao longo do processo. 
Ressalta-se que a interpretação deste tipo de carta funciona como nas de individual e amplitude móvel (IM-R), nas quais o analista considera o processo fora de controle quando existe um ponto acima ou abaixo dos limites de controle.

O Limite Específico de controle (LEC) foi adotado com base nos valores de perdas aceitáveis na colheita de soja (EMBRAPA, 2002), uma vez que para o recolhimento de amendoim ainda não se encontram na literatura níveis aceitáveis de perdas nessa operação.

\section{RESULTADOS E DISCUSSÃO}

Sob o ponto de vista do controle estatístico de processo, os dois processos encontram-se sob controle para as variáveis perdas da máquina, da plataforma e totais (Figuras 1). Porém, na média, é possível notar que as perdas da máquina ocorrem em maior quantidade quando está opera em condições de campo que possui menor teor de água das vagens. Este valor representa aproximadamente $64,3 \%$ das observações acima da média.

Houve redução na capacidade de separação das vagens da recolhedora nessas condições, visto que a regulagem afeta as condições de processamento de trilha e separação. Portanto, é fundamental que o operador do conjunto mecanizado tenha percepção de quando se deve efetuar uma nova regulagem nos pinos do cilindro trilhador, colocando-os na posição adequada para cada situação da lavoura.

As perdas na plataforma de recolhimento (Figura 1 B) foram semelhantes nos dois processos, com média de $46 \mathrm{~kg} \mathrm{ha}^{-1}$, compondo a maior parte das perdas totais. Como a colheita de amendoim ocorre em duas operações, a primeira (arranquio) afeta diretamente no rendimento da segunda, principalmente na avaliação das perdas na plataforma durante o recolhimento. Dessa forma em qualquer situação as perdas na plataforma de recolhimento na colheita de amendoim serão maiores do que as perdas da máquina.

Resultados semelhantes foram observados por SOUZA et al. (2010), que verificaram que as perdas de feijão (colheita semimecanizada) ocasionadas na plataforma de recolhimento foram superiores àquelas provocadas nos sistemas de trilha, separação e de limpeza de uma colhedora com sistema de trilha de fluxo axial.

Quando se leva em consideração que a quantidade permitida das perdas totais no recolhimento de amendoim situa-se em torno de $1 \%$ da produtividade em uma unidade produtora, nota-se pelas cartas de controle (Figura $1 \mathrm{C}$ ) que apesar do processoapresentar estável, existe a necessidade de se ajustar os mecanismos do conjunto mecanizado às condições que se encontra a lavoura, visto que não existe nenhum ponto abaixo do limite específico (LE).

Nas duas condições é notório que o produtor terá redução nos retornos líquidos, porém, analisando cada processo individualmente, com base na média, nota-se que as perdas podem ser consideradas aceitáveis, representando $1 \%$ e 1,05\% para produtividade média de $5500 \mathrm{~kg} \mathrm{ha}^{-1}$, com 
16 e 17 de agosto de 2018, centro de convenções da FCAV/UNESP - Câmpus de Jaboticabal, SP

teor de água das vagens de 20 e 15\%, respectivamente, quando comparados com os resultados encontrados por GRIFFIN (1991) e SOUZA et al. (2001), que estabelecem que as perdas totais de uma recolhedora-trilhadora devem estar abaixo de 3 a $5 \%$.

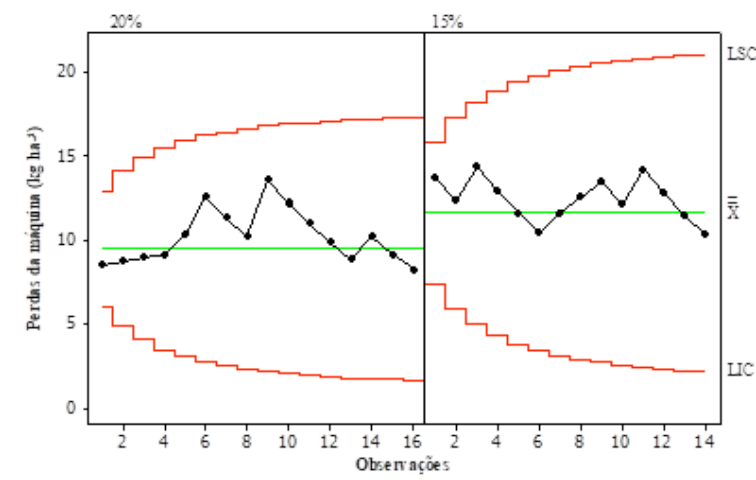

(A)

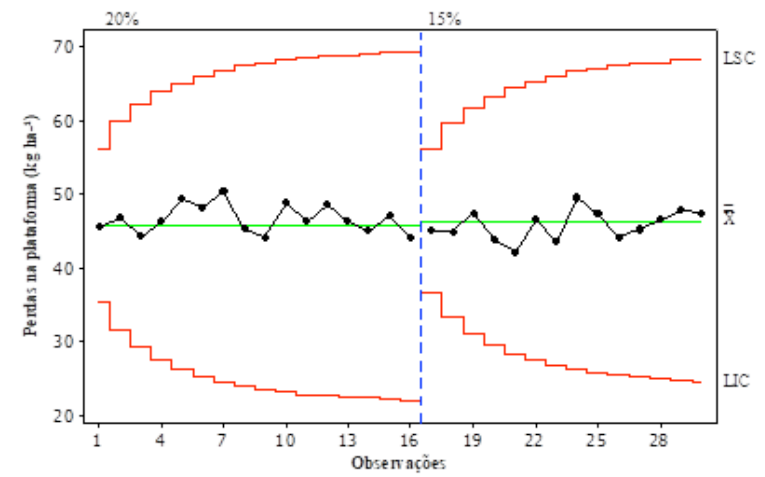

(B)

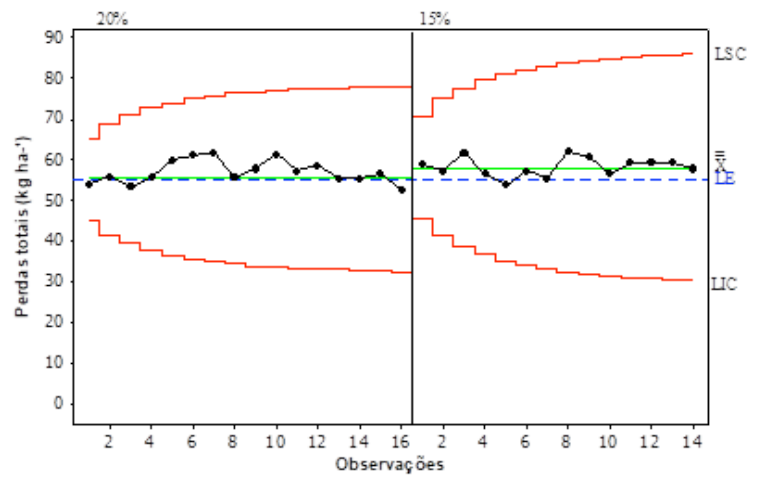

(C)

Figura 1. Carta de controle MMEP para perdas da máquina (A), da plataforma (B) e perdas totais (C) no recolhimento de amendoim

\section{CONCLUSÃO}

O teor de água das vagens entre 15 e $20 \%$ não interfere na quantidade de perdas, pois apresentaram valores médios próximos entre si, com pouca variabilidade.

\section{REFERÊNCIAS BIBLIOGRÁFICAS}

COLVIN, BC. YU-CHIENTSENGA, BARRY L. TILLMANA,B, DIANE L. ROWLANDA, JOHN E. ERICKSONA, ALBERT K. CULBREATHC, JASON A. FERRELLA (2018) Consideration of peg strength and disease severity in thedecision to harvest peanut in southeastern USA, Journal of crop improvement. v.32, p.1-18.

EMBRAPA - (2002) Empresa Brasileira de Pesquisa Agropecuária. Tecnologias de produção de soja: Paraná: 2003. Londrina: Embrapa Soja, Sistemas de produção 195p. 
EMBRAPA - (2013) Empresa Brasileira de Pesquisa Agropecuária. Sistema Brasileiro de Classificação de Solos. 3. ed. Brasília: Embrapa,. 353 p.

GRIFFIN, G. A. (1991) Combine harvesting: operating maintaining and improving efficiency of combines. 4. ed. Illinois: John Deere andCompany.

SOUZA, C. M. A.; BOTTEGA, E. L.; VILELA, F. V.; RAFULL, L. Z. L.; QUEIROZ, D. M. (2010) Espacialização de perdas e da qualidade do feijão em colheita semimecanizada. ActaScientiarum. Agronomy Maringá, v. 32, n. 2, p. 201-208.

SOUZA, C. M. A.; QUEIROZ, D. M.; CECON, P. R.; MANTOVANI, E. C. (2001) Avaliação de perdas em uma colhedora de fluxo axial para feijão. Revista Brasileira de Engenharia Agrícola e Ambiental, v. 5, n. 3, p. 530-537. 